\title{
Lumbar spine Schmorl's nodes; prevalence in adults with back pain, and their relation to vertebral endplate degeneration
}

\author{
Israa Mohammed Sadiq
}

\begin{abstract}
Background: In 1927, Schmorl described a focal herniation of disc material into the adjacent vertebral body through a defect in the endplate, named as Schmorl's node (SN). The aim of the study is to reveal the prevalence and distribution of Schmorl's nodes (SNs) in the lumbar spine and their relation to disc degeneration disease in Kirkuk city population.

Results: A cross-sectional analytic study was done for 324 adults (206 females and 118 males) with lower back pain evaluated as physician requests by lumbosacral MRI at the Azadi Teaching Hospital, Kirkuk city, Iraq. The demographic criteria of the study sample were 20-71 years old, 56-120 kg weight, and 150-181 cm height. SNs were seen in 72 patients (22\%). Males were affected significantly more than the females $(28.8 \% \mathrm{vs.} 18.8 \%, P=0.03)$. SNs were most significantly affecting older age groups. L1-L2 was the most affected disc level (23.6\%) and the least was L5-S1 (8.3\%). There was neither a significant relationship between SN and different disc degeneration scores $(P=0.76)$ nor with disc herniation $(P=0.62, \mathrm{OR}=1.4)$, but there was a significant relation $(P=0.00001, \mathrm{OR}=7.9)$ with $\mathrm{MC}$.

Conclusion: $\mathrm{SN}$ is a frequent finding in adults' lumbar spine MRI, especially in males; it is related to vertebral endplate bony pathology rather than discal pathology.
\end{abstract}

Keywords: Disc degeneration disease (DDD), Lumbar spine, Magnetic resonance imaging (MRI), Schmorl's node (SN)

\section{Background}

Schmorl's nodes (SN) are herniation of the disc material through a defect in the bony endpalte into the vertebral body described by Schmorl, a German pathologist [1]. their dirct cause is unknown, but it was assumed to be due to weakness of the intervertebral disc [2], degeneration of the spine due to exessive loads [3-5], or due to autoimmune reaction [6]. More recently, some researchers found a significant correlation between the morphology of the verterbral body and the presence of SN [7].

These nodes present, most commonly, as incidental findings in patients who did lumbar MRI fir various complaints [8], however, they can be the cause of chronic lower back pain [9].

Correspondence: Israa78kirkuk@Gmail.com

Department of Surgery/Radiology, Faculty of Medicine, Kirkuk University, Kirkuk, Iraq
There is a wide range $(3.8-76 \%)$ in the reported prevalence of the Schmorl's nodes in the general population [10-12].

The Schmorl node may be well detected by plain radiography, computed tomography (CT), and bone scintigraphy; however, MRI is the modality of choice for the diagnosis of Schmorl nodes, as they are best seen on the sagittal MRI sequences [13]. The nodes usually exhibit the same signal characteristics as the adjacent disc, with a thin rim of sclerosis at the margins [14].

Previous studies have reported a positive correlation between $\mathrm{SNs}$ and lumbar disc degeneration disease (DDD) and the severity of DDD $[15,16]$.

DDD is best evaluated by MRI, and this imaging modality is generally considered the most sensitive technique for examining disc degeneration. DDD was staged as the following according to Schneiderman grading system $[12,17,18]$.

Stage 0: There is no signal change in the disc.

Stage1: There is a mild decrease in signal intensity of the disc on $\mathrm{T} 2$ sequences. 


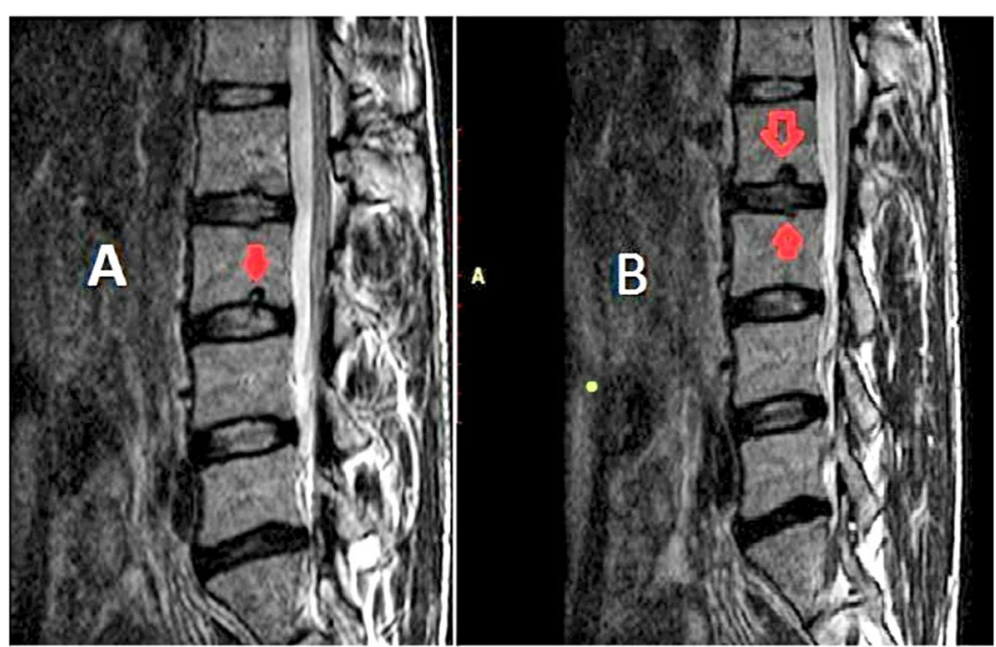

Fig. 1 A 48-year-old man with 6 months of lower back pain. T2-weighted sagittal magnetic resonance turbo spin echo $(\mathbf{a}, \mathbf{b})$ (echo time $=100$ $\mathrm{ms}$, repetition time $=2363 \mathrm{~ms}$ ) showing $S N$ in the lower end plate of $L 3$ vertebra in $\mathbf{a}$ and in the lower endplate of $L 2$ and upper endplate of $L 3$, associated with score 1 degeneration at L2-L3 disc in $\mathbf{b}$.

Stage 2: The disc is markedly hypointense with preserved disc height.

Stage 3: Decreased disc signal intensity and disc height.

Associated MRI features of DDD include disc bulging, herniation, and Modic change (MC) [19].

Disc herniation is seen as the focal of disc material beyond the edges of the apophyseal ring [20]. MC is seen as altered signal intensity at the vertebral endplate on both T1W and T2W images. Three types of Modic change were identified. Type I change show decreased signal intensity on T1-weighted images and increased signal intensity on T2-weighted due to fibro vascular replacement. Type II changes correlate with fatty marrow replacement and show increased signal intensity on T1-weighted images and hypointense signal on T2-weighted images. Type III changes correlate with dense bone (sclerosis) that are represented by decreased signal intensity on both $\mathrm{T} 1$ - and $\mathrm{T} 2$ weighted images [21-23]. The aim of this study is to reveal the prevalence of $\mathrm{SN}$ in adults with lower back pain and to evaluate its relationships with lumber DDD.

Table 1 Demographic criteria of the study sample

\begin{tabular}{lllll}
\hline Category & $\begin{array}{l}\text { Female, } N=206 \\
\text { Mean } \pm \mathrm{SD}\end{array}$ & Male, $N=118$ & $\begin{array}{l}95 \% \\
\mathrm{Cl}\end{array}$ & $P$ value \\
\hline Age (years) & $44.5 \pm 12.21$ & $45.5 \pm 12.75$ & -1.8 & $P=0.4$ \\
Weight $(\mathrm{kg})$ & $75 \pm 9.4$ & $83.42 \pm 16.2$ & 5.6 & $<0.0001$ \\
Height $(\mathrm{cm})$ & $159.6 \pm 5.8$ & $174.5 \pm 7.1$ & 13.46 & $<0.0001$ \\
\hline
\end{tabular}

$N$ number

\section{Methods}

\section{Subjects}

Three hundred-twenty four (324) adult patients referred by physicians to MRI unit to do lumbosacral MRI were included in this cross-sectional analytic study.

\section{Inclusion criteria}

Adult (more than 18 years old) patients with lower back pain were examined at the MRI department at the Azadi Teaching Hospital, Kirkuk city, Iraq, over the period from September 2016 to February 2018.

\section{Exclusion criteria}

Those who had a history of spinal surgery or back trauma, spinal infection, and malignant diseases were excluded from the study.

The clinical data were obtained from the documentations of the clinicians.

\section{Imaging}

All lumbosacral spine MRI examinations were done using 1.5T unit (Philips Achieva, Netherlands, 2010)

Table 2 Gender of the SN-affected patients

\begin{tabular}{llll}
\hline Gender & \multicolumn{1}{l}{ SN } & Total \\
\cline { 2 - 3 } & Present & Not present & \\
\hline Female & $38(11.7 \%)$ & $168(51.9 \%)$ & $206(63.6 \%)$ \\
Male & $34(10.5 \%)$ & $84(25.9 \%)$ & $118(36.4 \%)$ \\
Total & $72(22.2 \%)$ & $252(77.8)$ & $324(100 \%)$ \\
\hline $\begin{array}{l}\text { SN } \\
\text { SN Schmorl's node }\end{array}$ & &
\end{tabular}


Table 3 Average age of SN-affected patients

\begin{tabular}{llll}
\hline $\begin{array}{l}\text { Age } \\
\begin{array}{l}\text { group } \\
\text { (years) }\end{array}\end{array}$ & SN & Total \\
\cline { 2 - 3 } & Present & Not present & \\
\hline$>40$ & $4(1.2 \%)$ & $82(25.3 \%)$ & $86(26.5 \%)$ \\
$40-59$ & $38(11.7 \%)$ & $124(38.3 \%)$ & $162(50.1 \%)$ \\
$<60$ & $30(9.3 \%)$ & $46(14.2 \%)$ & $76(23.4 \%)$ \\
Total & $72(22.2 \%)$ & $252(77.8 \%)$ & $324(100 \%)$ \\
\hline
\end{tabular}

$P<0.0001$ using chi-square test

$S N$ Schmorl's node

with a dedicated lumbar coil, and the imaging protocol was as follows:

1. T1-weighted sagittal turbo spin echo (TSE) with 8 ms echo time (TE) and $500 \mathrm{~ms}$ repetition time (TR).

2. T2-weighted sagittal TSE with $100 \mathrm{~ms}$ TE and 4000 TR.

3. T2-weighted axial TSE with $120 \mathrm{~ms}$ TE and 4000 TR, and

4. Myelography with $1000 \mathrm{~ms}$ TE and 8000 TR.

All images were interpreted by a specialized radiologist with a minimum of 7 years' experience. Each lumbar level was assessed for disc degeneration scoring and presence of Schmorl's nodes, which was seen as a localized lesion in the vertebral endplate with or without sclerotic rim (Fig. 1). The presence of MC and disc herniation was also checked at each disc level.

\section{Statistical analysis}

The SN frequency according to age and gender, and its distribution were assessed. The relation between the presence of $\mathrm{SN}$ and the scores of disc degeneration, disc herniation, and $\mathrm{MC}$ at each single level were calculated using chi-square test. A $P$ value level of less than 0.05 was required for significance. SPSS software, version 17, was used for the statistical analyses.

\section{Result}

The demographic criteria of the study sample was as follows: 206 females and 118 males, female to male ratio was 1.7:1, overall mean age was $45.5 \pm 12.48$ years, their mean weight was $79.2 \pm 101 \mathrm{~kg}$, and the mean height was $167.1 \pm 6 \mathrm{~cm}$ (Table 1$)$.

The SN was seen in $22.2 \%$ of the patients $(41 \%$ at one level and 59\% in more than one). Twenty-eight percent of males and $18.8 \%$ of females had SN; males were affected significantly more than females $(P=0.03)$ (Table 2$)$.

The average age of $\mathrm{SN}$-affected patients was 55 years, $5.5 \%$ of them were under 40 years old, $52.8 \%$ were between 40 and 59 years old, and $41.7 \%$ were over 60 years old. The prevalence of SN was the least at a younger age group (40 years old) and significantly increased as age advanced $(P=0.0001)$ (Table 3$)$.

The total number of the discs of 324 patients was 1944; SN was seen in 144 discs. The single disc level was seen in $41 \%$ of patients, and more than one disc level in $59 \%$. L1-L2 was the most affected disc level (23.6\%) followed by, in a descending order, L2-L3, L3-L4, L4L5, T12-L1, and L5-S1 (20.8\%, 18.1\%, 16.7\%, 12.5\%, and $8.3 \%$ respectively) (Fig. 2 ).

The degeneration scores of SN-affected levels were as follows: score zero was seen in 54 patients (37.5\%), score 1 in 52 patients $(36.1 \%)$, score 2 in 20 patients $(13.9 \%)$, and score 3 in 18 patients (12.5\%). The degree of disc degeneration was not affected by the presence of $\mathrm{SN}$, as the $P=0.76$ at all scores (Table 4 ).

The SN-affected lumbar levels had also a disc bulge/ herniation in $20.8 \%$ (30 levels). There was no statistically significant relation between the $\mathrm{SN}$ and disc bulge/herniation, as the $P=0.62(\mathrm{OR}=1.4)$ (Table 5).

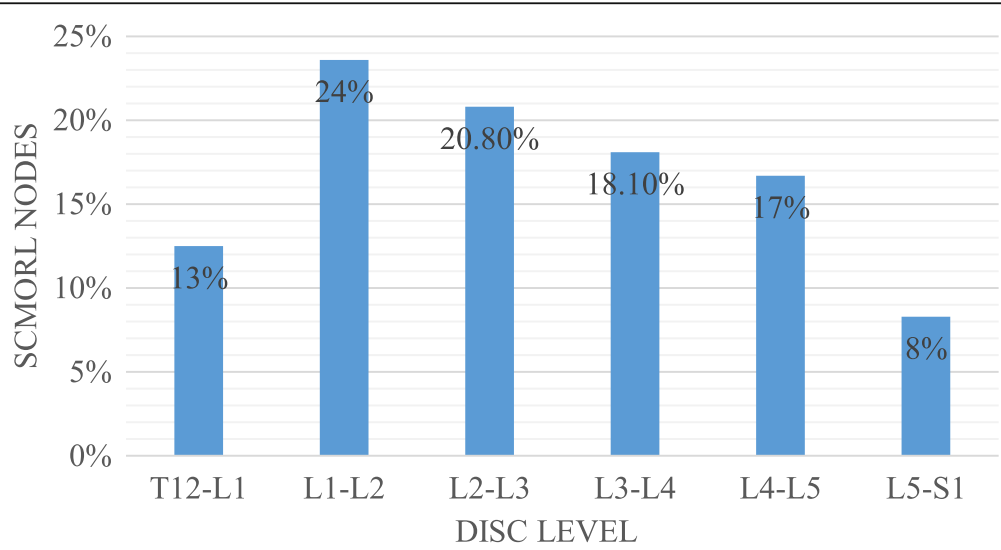

Fig. 2 Bar chart showing the overall prevalence of Schmorl's nodes (SN) by vertebral level 
Table 4 The degeneration scores of SN-affected levels

\begin{tabular}{llll}
\hline $\begin{array}{llll}\text { Degeneration } \\
\text { score }^{\text {a }}\end{array}$ & SN & Total \\
\cline { 2 - 3 } & Present & Not present & \\
\hline 0 & $54(2.8 \%)$ & $650(33.4 \%)$ & $704(36.2 \%)$ \\
1 & $52(2.6 \%)$ & $600(30.8 \%)$ & $652(33.5 \%)$ \\
2 & $20(1 \%)$ & $295(15.2 \%)$ & $315(16.3 \%)$ \\
3 & $18(0.9 \%)$ & $255(13.1 \%)$ & $273(14 \%)$ \\
Total & $144(7.4 \%)$ & $1800(92.6 \%)$ & $1944(100 \%)$ \\
\hline $\begin{array}{l}\text { P } \\
\text { SN S O.76 using chi-square test }\end{array}$ & & \\
a Schneiderman grading system & &
\end{tabular}

The MC and SN were seen together at 22 disc levels (13.9\%). There was a significant relation between MC and $\mathrm{SN}$ as $P=0.00001(\mathrm{OR}=7.9)$ (Table 6).

\section{Discussion}

The epidemiological data shows $3.8-76 \%$ of the general population was diagnosed with $\mathrm{SN}$ [11], which is broadly in line with the data from the present study that is showing almost one quarter of the population (22.2\%) had SN.

The wide difference in SN prevalence may have different causes, such as different definitions of SN used and different spinal column regions involvement in studies, and some others suggested genetic influence as manifested by variations in ethnic distribution $[5,12]$.

In the current study, the number of men with SNs was more than women, which in line with previous studies $[2,3,24]$; the research of Dar G. and his collogues considered this high affection among males was due to their larger body size, and taller vertebral bodies and discs both make more mechanical stress on the endplates [5], whilst another study suggested genetic determinants for the male predilection [12].

The prevalence of SN was significantly increased as age advanced, comparable with previous studies that suggested weakened aged cartilaginous endplates and reduced bone density in older age groups; both factors may play a role in pathogenesis of SNs [25-27]. The higher lumber levels were affected more, as L1L2 was the most affected disc (23.6\%) in the current

Table 5 Significant relation between the SN and disc bulge/ herniation

\begin{tabular}{llll}
\hline $\begin{array}{llll}\text { Disc } \\
\text { bulge/ } \\
\text { herniation }\end{array}$ & SN & Total \\
\cline { 2 - 3 } & Present & Not present & \\
\hline Yes & $30(1.5 \%)$ & $285(14.7 \%)$ & $315(16.2 \%)$ \\
No & $114(5.9 \%)$ & $1515(78 \%)$ & $1629(83.8 \%)$ \\
Total & $144(7.4 \%)$ & $1800(92.5 \%)$ & $1944(100 \%)$ \\
\hline $\begin{array}{l}P=0.62 \\
\text { SN Schmorl's node }\end{array}$ & & \\
\end{tabular}

Table 6 Significant relation between MC and SN

\begin{tabular}{llll}
\hline MC & \multicolumn{1}{l}{ SN } & Total \\
\cline { 2 - 3 } & Present & Not present & \\
\hline Yes & $22(1.1 \%)$ & $40(2 \%)$ & $62(3.2 \%)$ \\
No & $122(6.3 \%)$ & $1760(90.5 \%)$ & $1882(96.2 \%)$ \\
Total & $144(7.4 \%)$ & $1800(92.5 \%)$ & $1944(100 \%)$ \\
\hline
\end{tabular}

$P=0.00001$ using chi-square test

MC Modic change, SN Schmorl's node

study; this was consistent with most of the papers [8, $24,27]$. This could be due to higher mechanical stresses, and the special anatomical features of this part of spine make it more prone to damage by torsional and axial body loads [2].

Several studies did not show significant relation between SNs and disc degeneration nor with disc bulge/ herniation, like the current study. As Sonne-Holm S. and his colleagues' assessed lumbar spine using radiographs in healthy adults [11], whilst Hilton RC and his colleagues studied post-mortem spines, they did not find a significant relation between the SN and DDD at the lumbar region.

Other studies assessed the MRI images of different sample criteria, including healthy twin females [12] and healthy adults [24], a paper analysed discography in adults with back pain [16], and another assessed CT scans of lumber spine [25]; these manuscripts showed a significant relation between SNs and disc degeneration.

This controversy about SN and DDD association might be related to different factors, such as different sample criteria, different radiological modalities used, and other spine region's involvement with the lumber spine in the studies.

According to this paper, we prefer the theory of endplate osteonecrosis as a cause of SNs, rather than disc degeneration, as a study examined the surgical specimens of SNs proposed that the SNs are the end result of ischemic death of bone beneath the endplate and the herniation of the disc into the body of the vertebra is a secondary phenomenon. The hypothesis of microtrauma is also preferred as Burke et al. found more $\mathrm{SN}$ in American soldiers [26]; these minor traumas cause herniation of nucleus pulposus through developmental weak points in the endplates [28]. Also, the developmental models revealed that $\mathrm{SNs}$ are already present during skeletal maturation prior the beginning of degeneration [2]. Moreover, the disc degeneration mostly occurs in the lower lumbar levels in reverse to SNs which occurs in the upper lumbar levels.

Modic change was significantly associated with SNs in this study like another study done by Tobias et al .[8]; this result was probably due to disruption of the endplates and the herniation of disc material initiating inflammatory change and edema resembling $\mathrm{MC}$ as seen on MRI images. 


\section{Conclusion}

$\mathrm{SN}$ is a frequent MRI finding in the lumbar spine, especially in males, and mostly occurs in the 40-59 years age group. $\mathrm{SN}$ is related to vertebral endplate bony pathology rather than discal pathology.

\section{Abbreviations}

DDD: Disc degeneration disease; MC: Modic change; MRI: Magnetic resonance imaging; SN: Schmorl's node

\section{Acknowledgements}

Not applicable to this section.

\section{Ethical approval and consent to participate}

This study was approved by the Research Ethics Committee of the Faculty of Medicine at Kirkuk University in Iraq on 12/4/2018; reference number of approval: 153. All patients included in this study gave written informed consent to participate in this research. No patient was less than 16 years old or unconscious at the time of the study.

\section{Availability of materials and data}

All data are available at the author on request.

\section{Authors' contributions}

The study was done by a single author. The author read and approved the final manuscript.

\section{Funding}

Not applicable for this section.

\section{Consent for publication}

All patients included in this research gave written informed consent to publish the data contained within this study. No patient less than 16 years old, deceased, or unconscious was included in this study.

\section{Competing interests}

The author declares that there are no competing interests.

Received: 30 August 2019 Accepted: 21 October 2019

Published online: 02 December 2019

\section{References}

1. Wang Z, Yuan L, Ma D et al (2016) 18F-FDG PET/CT can differentiate vertebral metastases from Schmorl's nodes by distribution characteristics of the 18F-FDG. Hell J Nucl Med 19(3):241-244

2. Kwaku A. Kyere, Khoi D. Than, Anthony C. et al (2012) Schmorl's nodes. European Spine J 21(11): 2115-2121.

3. Mok, F. P, Samartzis D, Karppinen J, et al (2010) ISSLS prize winner: prevalence, determinants, and association of Schmorl nodes of the lumbar spine with disc degeneration: a population-based study of 2449 individuals. Spine 35: 1944-1952.

4. Henríquez M, Arriaza B (2013) Frequency and distribution of Schmorl's nodes in the spine of prehispanic Arica populations: evidence of work load on the vertebral column. Chungara Revista de Antropología Chilen 45:311-319

5. Dar G, Peleg S, Masharawi Y et al (2009) Demographical aspects of Schmorl nodes: a skeletal study. Spine 34:312-315

6. Z Zhang N, Li FC, Huang YJ et al (2010) Possible key role of immune system in Schmorl's nodes. Medical Hypotheses 74:552-554

7. Plomp KA, Roberts CA, Strand VU (2015) Does the correlation between Schmorl's nodes and vertebral morphology extend into the lumbar spine? Am J Physical Anthropol 157(3):526-534

8. Mattei TA, Rehman AA (2014) Schmorl's nodes: current pathophysiological, diagnostic, and therapeutic paradigms. Neurosurg Rev 37:39-46

9. He SC, Zhong BY, Zhu HD et al (2017) Percutaneous vertebroplasty for symptomatic Schmorl's nodes: 11 cases with long-term follow-up and a literature review. Pain Physician J 20:69-75

10. N Newell, CA Grant, MT Izatt (2015) Identifying vertebral end plate lesions (Schmorl's nodes) using a semiautomatic method. In Williams, Richard (Ed.) 26th Annual Scientific Meeting of the Spine Society of Australia, National Convention Centre, Canberra, A.C.T, on 10-12 April 2015.

11. Sonne-Holm S, Jacobsen S, Rovsing $\mathrm{H}$ et al (2013) The epidemiology of Schmorl's nodes and their correlation to radiographic degeneration in 4,151 subjects. Eur Spine J 22:1907-1912

12. Williams FM, Manek NJ, Sambrook PN et al (2007) Schmorl's nodes: common, highly heritable, and related to lumbar disc disease. Arthritis Rheum 57:855-860

13. Abu-Ghanem S, Ohana N, Abu-Ghanem Y et al (2013) Acute Schmorl node in dorsal spine: an unusual cause of a sudden onset of severe back pain in a young female. Asian Spine J 7:131e5

14. Wu, HT.H., Morrison, W.B. and Schweitzer, M.E (2006) Edematous Schmorl's nodes on thoracolumbar MR imaging: characteristic patterns and changes over time. Skeletal Radiol 35: 212

15. Abbas J, Slon V, Stein D et al (2017) In the quest for degenerative lumbar spinal stenosis etiology: the Schmorl's nodes model. BMC Musculoskeletal Disord 18(1):164

16. Wang Y, Videman T, Battié MC (2012) ISSLS prize winner: lumbar vertebral endplate lesions: associations with disc degeneration and back pain history. Spine J 37:1490-1496

17. Jensen TS, Karppinen J, Sorensen JS et al (2008) Vertebral endplate signal changes (Modic change): a systematic literature review of prevalence and association with non-specific low back pain. Euro Spine J 17(11):1407-1422

18. Samartzis D, Karppinen J, Chan D et al (2012) The Association of lumbar intervertebral disc degeneration on magnetic resonance imaging with body mass index in overweight and obese adults a population-based study. Arthritis Rheum 64(5):1488-1496

19. Zhang YG, Sun ZM, Liu JT et al (2009) Features of intervertebral disc degeneration in rat's aging process. J Zhejiang Univ Sci B 10:522-527

20. Van Rijn JC, Klemetsö N, Reitsma JB et al (2005) Observer variation in MRI evaluation of patients suspected of lumbar disk herniation. AJR Am J Roentgenol 184:299-303

21. Vital JM, Gille O, Pointillart V et al (2003) (2003) Course of Modic 1 six months after lumbar posterior osteosynthesis. Spine 28:715-720

22. Marshman LA, Trewhella M, Friesem T et al (2007) Reverse transformation of Modic type 2 changes to Modic type 1 changes during sustained chronic low-back pain severity. Report of two cases and review of the literature. J Neurosurg Spine 6:152-155

23. Kuisma M, Karppinen J, Niinimäki J et al (2006) A three-year follow-up of lumbar spine endplate (Modic) changes. Spine 31:1714-1718

24. Ruofeng Y, Lord EL, Raphael CJ et al (2015) Distribution of Schmorl nodes in the lumbar spine and their relationship with lumbar disk degeneration and range of motion. Spine 40(1):49-53

25. Abbas J, Hamoud K, Peled N et al (2018) Lumbar Schmorl's nodes and their correlation with spine configuration and degeneration. Biomed Res Int 2:1-9

26. Monstarhfir B, Bresson P, Koch A et al (2016) MR imaging of Schmorl's nodes: imaging characteristics and epidemio-clinical relationships. Diagn Interv Imaging 97(4):411-417

27. Owlia MB, Farahifard P (2013) Historical Schmorl's node: time to differentiation and renaming (a mini-review). Spine 2(2):1000e109

28. Hillton RC, Ball J, Benn RT (1976) Vertebral end-plate lesions (Schmorl's nodes) in the dorsolumbar spine. Ann Rheum Dis 35:127

29. Dar G, Masharawi Y, Peleg S et al (2010) European Spine Journal 19:670

\section{Publisher's Note}

Springer Nature remains neutral with regard to jurisdictional claims in published maps and institutional affiliations. 